\title{
PTR-ToF-MS for the Online Monitoring of Alcoholic Fermentation in Wine: Assessment of VOCs Variability Associated with Different Combinations of Saccharomyces/Non-Saccharomyces as a Case-Study
}

\author{
Carmen Berbegal ${ }^{1,2}$, Iuliia Khomenko ${ }^{3}$, Pasquale Russo ${ }^{1}$, Giuseppe Spano ${ }^{1}$, \\ Mariagiovanna Fragasso ${ }^{1}$, Franco Biasioli ${ }^{3, *(1)}$ and Vittorio Capozzi ${ }^{4, *(1)}$
}

1 Department of the Sciences of Agriculture, Food and Environment, University of Foggia, Via Napoli 25,

71122 Foggia, Italy; carmen.berbegal@uv.es (C.B.); pasquale.russo@unifg.it (P.R.);

giuseppe.spano@unifg.it (G.S.); mariagiovanna.fragasso@gmail.com (M.F.)

2 EnolabERI BioTecMed, Universitat de València, 46100 Valencia, Spain

3 Department of Food Quality and Nutrition, Research and Innovation Centre, Fondazione Edmund

Mach (FEM), via E. Mach 1, 38010 San Michele all'Adige, Italy; iuliia.khomenko@fmach.it

4 Institute of Sciences of Food Production, National Research Council (CNR), c/o CS-DAT,

Via Michele Protano, 71121 Foggia, Italy

* Correspondence: franco.biasioli@fmach.it (F.B.); vittorio.capozzi@ispa.cnr.it (V.C.); Tel.: +39-0461-615-187 (F.B.); +39-0881-630-201 (V.C.)

Received: 31 December 2019; Accepted: 24 May 2020; Published: 26 May 2020

check for updates

\begin{abstract}
The management of the alcoholic fermentation (AF) in wine is crucial to shaping product quality. Numerous variables (e.g., grape varieties, yeast species/strains, technological parameters) can affect the performances of this fermentative bioprocess. The fact that these variables are often interdependent, with a high degree of interaction, leads to a huge 'oenological space' associated with AF that scientists and professionals have explored to obtain the desired quality standards in wine and to promote innovation. This challenge explains the high interest in approaches tested to monitor this bioprocess including those using volatile organic compounds (VOCs) as target molecules. Among direct injection mass spectrometry approaches, no study has proposed an untargeted online investigation of the diversity of volatiles associated with the wine headspace. This communication proposed the first application of proton-transfer reaction-mass spectrometry coupled to a time-of-flight mass analyzer (PTR-ToF-MS) to follow the progress of AF and evaluate the impact of the different variables of wine quality. As a case study, the assessment of VOC variability associated with different combinations of Saccharomyces/non-Saccharomyces was selected. The different combinations of microbial resources in wine are among the main factors susceptible to influencing the content of VOCs associated with the wine headspaces. In particular, this investigation explored the effect of multiple combinations of two Saccharomyces strains and two non-Saccharomyces strains (belonging to the species Metschnikowia pulcherrima and Torulaspora delbrueckii) on the content of VOCs in wine, inoculated both in commercial grape juice and fresh grape must. The results demonstrated the possible exploitation of non-invasive PTR-ToF-MS monitoring to explore, using VOCs as biomarkers, (i) the huge number of variables influencing AF in wine, and (ii) applications of single/mixed starter cultures in wine. Reported preliminary findings underlined the presence of different behaviors on grape juice and on must, respectively, and confirmed differences among the single yeast strains 'volatomes'. It was one of the first studies to include the simultaneous inoculation on two non-Saccharomyces species together with a S. cerevisiae strain in terms of VOC contribution. Among the other outcomes, evidence suggests that the addition of M. pulcherrima to the coupled S. cerevisiae/T. delbrueckii can modify the global release of volatiles as a function of the characteristics of the fermented matrix.
\end{abstract}


Keywords: volatile organic compounds; proton-transfer reaction-mass spectrometry; Saccharomyces cerevisiae; Metschnikowia pulcherrima; Torulaspora delbrueckii; wine; flavor

\section{Introduction}

Wine is the result of alcoholic fermentation (AF) performed by yeasts that convert the sugars present in grape must into ethanol and carbon dioxide. During this fermentation, other chemical changes are produced as a consequence of yeast metabolic activities. Among the chemical changes, a consistent part of volatile organic compounds (VOCs) is released, influencing wine flavor $[1,2]$. The interest in the monitoring of this bioprocess is high due to (i) the vast number of variables that can affect AF performances, and (ii) the crucial relevant impact of AF on wine quality. Non-separative approaches based on direct injection mass spectrometry (DIMS) have recently emerged as an alternative for the high-throughput and cost-effective quantitative profiling of volatiles in food and beverages [3]. To the best of our knowledge, no study has explored the potential of DIMS techniques to assess online VOC variability in association with alcoholic fermentation in wine [4].

Saccharomyces cerevisiae has a leading role in performing AF in wine [5,6]. However, an increasing interest has been given to non-Saccharomyces yeasts as drivers of the differentiation of the quality of final wines $[7,8]$. Non-Saccharomyces yeasts can possess enzymatic activities different from the S. cerevisiae enzymatic inventory, catalyzing the synthesis and the release (from non-volatile bound precursors) of VOCs able to modulate aromatic wine complexity [9,10]. Moreover, they may influence other characteristics such as glycerol and mannoprotein content, volatile acidity, color stability, and ethanol levels of wines [11,12]. Usually, as a reason for non-optimal fermentative performances, non-Saccharomyces yeasts are used in combination with $S$. cerevisiae strains. Some studies have shown that the strategy of co-inoculating $S$. cerevisiae starter together with selected non-Saccharomyces yeasts at high cell density produces wines with distinctive characteristics [13]. The interaction between the different yeast species influences the content of VOCs associated with fermentations [14]. Among the non-Saccharomyces species, Torulaspora delbrueckii, Metschnikowia pulcherrima, Candida zemplinina, and Hanseniaspora uvarum are mostly cited and have been intensively investigated [9,15-21]. Strains belonging to the species Lachancea thermotolerans, Metschnikowia fructicola, Schizosaccharomyces pombe, T. delbrueckii, Kluyveromyces thermotolerans, Pichia kluyveri, and M. pulcherrima are commercialized or have patented applications [16,22]. Belonging to the class of direct injection mass spectrometry (DIMS) approaches, proton transfer reaction mass spectrometry (PTR-MS) is an established method for the rapid, direct, and non-invasive online monitoring of VOCs characterized by short response time and high sensitivity [23]. The coupling of proton transfer ionization with time-of-flight (ToF) mass spectrometers and automated sampling offers several advantages in terms of mass resolution, throughput, and reproducibility [24-26]. This analytical strategy has found several applications in the food field (e.g., [27-31]), with a specific interest in bioprocess monitoring associated with microbial-based processes (e.g., [32-34]). Furthermore, several studies have applied PTR-based approaches to monitor VOC release associated with yeast metabolisms [35], often in association with food matrices [36-38]. In the case of matrices containing ethanol, consistent experimental efforts have been performed to avoid the adverse effects of a high concentration of this alcohol (primary ion depletion and ethanol-ethanol/water clusters formation responsible for the loss of efficiency in the qualitative/quantitative detection) [34,39-42].

In the present work, PTR-ToF-MS was used for the online monitoring of AF in wine and to compare the performance of four (autochthonous and commercial) yeast strains, both in single cultures and in multiple inoculations, using two diverse model matrices as substrates (real grape must and commercial grape juice). This study also aimed to preliminarily explore the interest in PTR-ToF-MS analysis of flavor-related volatile compounds in the control, design, and application of single/mixed starter cultures for wine. 


\section{Materials and Methods}

\subsection{Microorganisms and the Determination of Microbial Population}

The following microorganisms were used for grape juice and grape must inoculation: the commercially available Saccharomyces cerevisiae strain DV10 (Lallemand, Montreal, QC, Canada, autochthonous characterized S. cerevisiae I6 strain from the Apulian region (Southern Italy) [43], and the commercially available non-Saccharomyces strains Metschnikowia pulcherrima FLAVIA (Lallemand, USA) and Torulaspora delbrueckii BIODIVA (Lallemand, Montreal, QC, Canada). Yeast starters were purchased in active-dried form. Rehydration procedures were done according to the suppliers' instructions. Starter cultures were prepared by growing pure cultures of the yeast strains separately grown in liquid Yeast Peptone Dextrose (YPD) medium ( $\%$ glucose, $2 \%$ Bacto peptone, $1 \%$ yeast extract) at $28{ }^{\circ} \mathrm{C}$.

The viable count of yeasts during the AF was enumerated on Wallerstein Laboratory (WL) agar medium (Sigma-Aldrich, St. Louis, USA). WL discriminates between the used yeast species by colony morphology and color (S. cerevisiae produces large white colonies, whereas non-Saccharomyces yeasts produce green colonies on this medium). Plates were incubated at $28^{\circ} \mathrm{C}$ for $48 \mathrm{~h}$.

\subsection{Micro-Vinifications and Wine Analysis}

Starter cultures were prepared by growing strains in YPD medium as described above and then inoculating the strains into commercial red grape juice (Vitafit, Lidl Stiftung \& Co., Neckarsulm, Germany) and red grape must from Apulian autochthonous grape varieties (20 Babo; $7.2 \mathrm{~g} / \mathrm{L}$ total acidity; $3.5 \mathrm{~g} / \mathrm{L}$ malic acid; $\mathrm{pH} 3.5$; free ammonium $163.5 \mathrm{mg} / \mathrm{L}$ ). Fermentations were performed inoculating at concentrations of $1 \times 10^{6} \mathrm{cfu} / \mathrm{mL}$ (colony-forming units per milliliter) of M. pulcherrima FLAVIA, $1 \times 10^{6} \mathrm{cfu} / \mathrm{mL}$ of T. delbrueckii BIODIVA and $1 \times 10^{4} \mathrm{cfu} / \mathrm{mL}$ of $S$. cerevisiae strains (DV10 or I6). Each fermentation experiment was carried out by performing three simultaneous independent repetitions. With these four biotypes, 14 different combinations of strains were carried out (Table 1). Fermentative kinetics from grape must were monitored daily by gravimetric determinations for seven days. With this purpose, samples were weighed daily to follow the weight loss caused by $\mathrm{CO}_{2}$ production.

Table 1. Microorganisms employed in different grape must/juice fermentations (trials 1-15).

\begin{tabular}{cc}
\hline Sample Code & Inoculated Yeast Cultures \\
\hline 1 & S. cerevisiae DV10 \\
2 & S. cerevisiae I6 \\
3 & M. pulcherrima FLAVIA \\
4 & T. delbrueckii BIODIVA \\
5 & S. cerevisiae DV10 + S. cerevisiae I6 \\
6 & S. cerevisiae DV10 + M. pulcherrima FLAVIA \\
7 & S. cerevisiae DV10 + T. delbrueckii BIODIVA \\
8 & S. cerevisiae I6 + M. pulcherrima FLAVIA \\
9 & S. cerevisiae I6 + T. delbrueckii BIODIVA \\
10 & S. cerevisiae DV10 + S. cerevisiae I6 + M. pulcherrima FLAVIA \\
11 & S. cerevisiae DV10 + S. cerevisiae I6 + T. delbrueckii BIODIVA \\
13 & S. cerevisiae DV10 + M. pulcherrima FLAVIA + T. delbrueckii BIODIVA \\
14 & S. cerevisiae I6 + M. pulcherrima FLAVIA + T. delbrueckii BIODIVA \\
15 & S. cerevisiae DV10 + S. cerevisiae I6 + M. pulcherrima FLAVIA + T. delbrueckii BIODIVA \\
\hline
\end{tabular}

\subsection{Samples Preparation and PTR-ToF-MS (Proton Transfer Reaction-Time of Flight-Mass} Spectrometry) Analysis

Nano-vinifications were performed in the vials using the above yeast combinations (Table 1) in commercial red grape juice and fresh red grape must. Nitrogen flux in the vial headspace assured maintaining the conditions comparable with those present in vinification. While the manufacturer 
sterilized the commercial grape juice, the must was not treated to reduce microbial presence. When present in the same trial, yeasts were co-inoculated in the juice/must. The resulting AF was monitored for three days. The whole experiment was performed in five replicates. For the measurements, a commercial PTR-ToF-MS 8000 apparatus from Ionicon Analytik GmbH (Innsbruck, Austria) was used in its standard configuration (V mode). The air associated with the headspace of the sample was directly injected in the PTR-MS drift tube. An argon dilution system was applied after headspace sampling. The dilution ratio was one part of headspace to three parts of argon. The argon flow rate was $120 \mathrm{sccm}$ and was controlled by a multigas controller (MKS Instruments, Inc, Andover, MA, USA). Ionization conditions were as follows: $110{ }^{\circ} \mathrm{C}$ drift tube temperature, $2.30 \mathrm{mbar}$ drift pressure, and $550 \mathrm{~V}$ drift voltage. These conditions led to an $\mathrm{E} / \mathrm{N}$ ratio of about $140 \mathrm{Td}$ ( 1 Townsend $=10-17 \mathrm{~cm}^{2} \mathrm{~V}^{-1} \mathrm{~s}^{-1}$ ). The inlet line was a PEEK capillary tube (internal diameter $0.04 \mathrm{in}$.) heated at $110{ }^{\circ} \mathrm{C}$, with a flow set at $40 \mathrm{sccm}$. The acquisition rate of the instrument was one spectrum per second.

\subsection{Data Analysis}

Deadtime correction, internal calibration of mass spectral data, and peak extraction were performed according to the procedure described by Cappellin et al. [44,45]. Peak intensity in ppbv was estimated using the formula described by Lindinger et al. [46] using a constant value for the reaction rate coefficient $\left(\mathrm{k}=2.10^{-9} \mathrm{~cm}^{3} \mathrm{~s}^{-1}\right)$. This approach introduces a systematic error for the absolute concentration for each compound that is, in most cases, below 30\% and could be accounted for if the actual rate constant coefficient is available [45]. All data detected and recorded by the PTR-ToFMS were processed and analyzed using MATLAB R2017a (MathWorks Inc., Natick, MA, USA) and R (R Foundation for Statistical Computing, Vienna, Austria). Principal component analysis, analysis of variance, and Tukey's post-hoc test were performed to spot the differences in the volatile aroma compounds emitted by the 28 grape must and juice fermentations used in this study.

\section{Results}

\subsection{Alcoholic Fermentation Kinetics and Yeast Dynamics}

The kinetics of the 14 fermentations in red grape must were monitored daily for seven days, evaluating the loss of weight due to the production of $\mathrm{CO}_{2}$ (data not shown). All fermentations were completed in four days except for sample 3 (inoculated with a single culture of M. pulcherrima FLAVIA), which was not able to complete the AF. The interactions between Saccharomyces spp. and both non-Saccharomyces spp. of enological interest, M. pulcherrima FLAVIA and T. delbrueckii BIODIVA, were investigated in terms of cell density. The differential morphology of the colonies on WL medium allowed us to calculate the proportion of each yeast species in different phases of AF (Figure 1). Only when both $S$. cerevisiae strains were co-inoculated the viable cell count was considered as total S. cerevisiae viable cells without distinguishing between DV10 and I6 strains.

Results from plate counting revealed that the maximum cell density of the single cultures was obtained after $48-72 \mathrm{~h}$ of the grape must inoculation both for S. cerevisiae (with an initial cell population of $1 \times 10^{4} \mathrm{cfu} / \mathrm{mL}$ ) and non-Saccharomyces yeasts (with an initial cell population of $1 \times 10^{6} \mathrm{cfu} / \mathrm{mL}$ ) (Figure 1, Experiments 1-4). In terms of single cultures studied, M. pulcherrima FLAVIA reached the lowest cell concentration (slightly more than $1 \times 10^{7} \mathrm{cfu} / \mathrm{mL}$ ) after $72 \mathrm{~h}$ of inoculation (Figure 1 , Experiment 3). Conversely, T. delbrueckii BIODIVA, even if with a different profile, achieved a biomass concentration comparable to those of the two S. cerevisiae strains. Considering the strain combinations, when two S. cerevisiae strains (DV10 and I6) were inoculated simultaneously, the growth behavior was the same as when they were inoculated in a single form and reached the maximum yeast population after $48 \mathrm{~h}$ of the inoculation (Figure 1, Experiment 5). Results from the co-inoculation of one strain of S. cerevisiae with M. pulcherrima FLAVIA (Figure 1 Experiments 6 and 8) showed that in $24 \mathrm{~h}$, the $S$. cerevisiae strains were able to overtake the non-Saccharomyces yeast concentration, and in $48-72 \mathrm{~h}$ 
achieved the maximum yeast population. On the other hand, the M. pulcherrima FLAVIA population decreased drastically after $72 \mathrm{~h}$ of inoculation. Contrary to M. pulcherrima FLAVIA, yeast T. delbrueckii BIODIVA presented a high cell density when it was co-inoculated with one of the $S$. cerevisiae strains, and with similar cell concentration levels to S. cerevisiae (Figure 1, Experiments 7 and 9). In the same way, when the two S. cerevisiae strains, DV10 and I6, were co-inoculated with M. pulcherrima FLAVIA or with T. delbrueckii BIODIVA strains, the growth behavior of the non-Saccharomyces strains was the same than when they were inoculated with only one S. cerevisiae strain (Figure 1, Experiments 10 and 11). The simultaneous inoculation of one S. cerevisiae strain with both, T. delbrueckii BIODIVA and M. pulcherrima FLAVIA (Figure 1, Experiments 12 and 13), revealed that S. cerevisiae strains needed more time to reach the maximum cell concentration than when co-inoculated with only one non-Saccharomyces strain, and T. delbrueckii BIODIVA presented a higher population than S. cerevisiae strains for $48 \mathrm{~h}$.
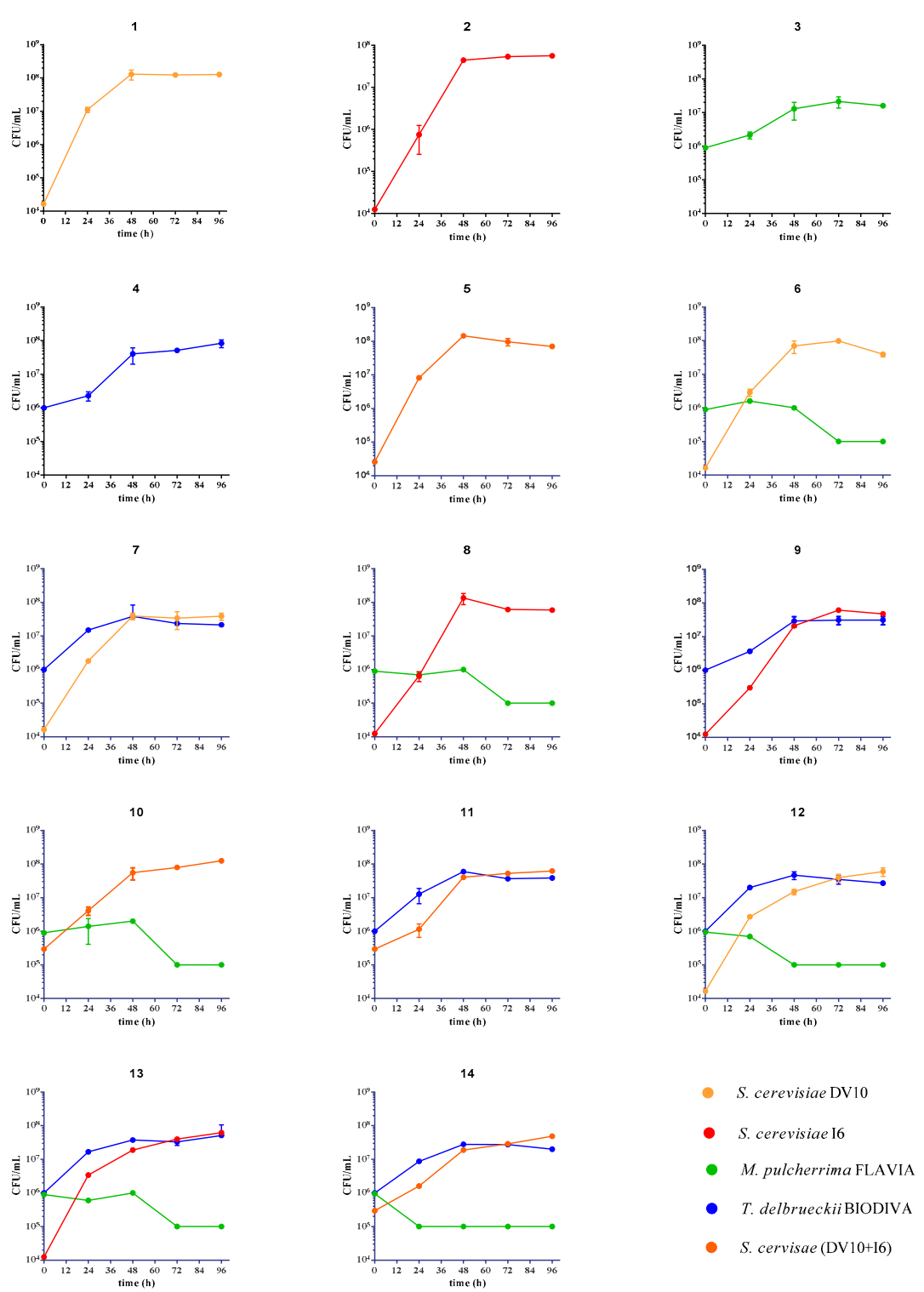

Figure 1. Viable cell count $(\mathrm{cfu} / \mathrm{mL})$ of different yeast single or mixed culture (Table 1) inoculated. The cell enumeration was performed on Wallerstein Laboratory agar medium that discriminates S. cerevisiae (large white colonies) from non-Saccharomyces yeasts (green colonies).

Inoculating the four starter cultures simultaneously (Figure 1, Experiment 14) triggered, as in the previous cases, that $S$. cerevisiae strains required more time to reach the maximum cell population and, 
the maximum cell concentration was lower than when they were inoculated in a single culture form. Furthermore, the population of $S$. cerevisiae and T. delbrueckii BIODIVA presented similar population levels after $48 \mathrm{~h}$ of inoculation. Otherwise, the $M$. pulcherrima FLAVIA population decreased from the inoculation time. Overall, biological interactions influenced single yeast growth behavior. Nevertheless, in all of the studied experimental modes, the most significant changes related to yeast population occurred during the first $72 \mathrm{~h}$, which led us to focus on this temporal interval for the online monitoring of VOCs associated with the considered experimental modes using the PTR-ToF-MS technology.

\subsection{Automated Monitoring Volatile Organic Compound (VOC) Evolution in Red Grape Must and Juice Fermentation by Different Yeast Mixed Cultures}

A preliminary data exploration has been made to visualize the results of the PTR-ToF-MS grape must and juice analysis through a principal component analysis (PCA). The first and second PCA components (Figure 2) accounted for $84 \%$ of total variability and showed that the two matrices (grape juice and must) used in this study led to clear changes of VOC release. Differences in the distribution of variances were also observed concerning single yeasts or yeast combinations. It is easy to follow a time-dependent dimension of the phenomena, observing the increasing dimensions of the symbols in Figure 2.

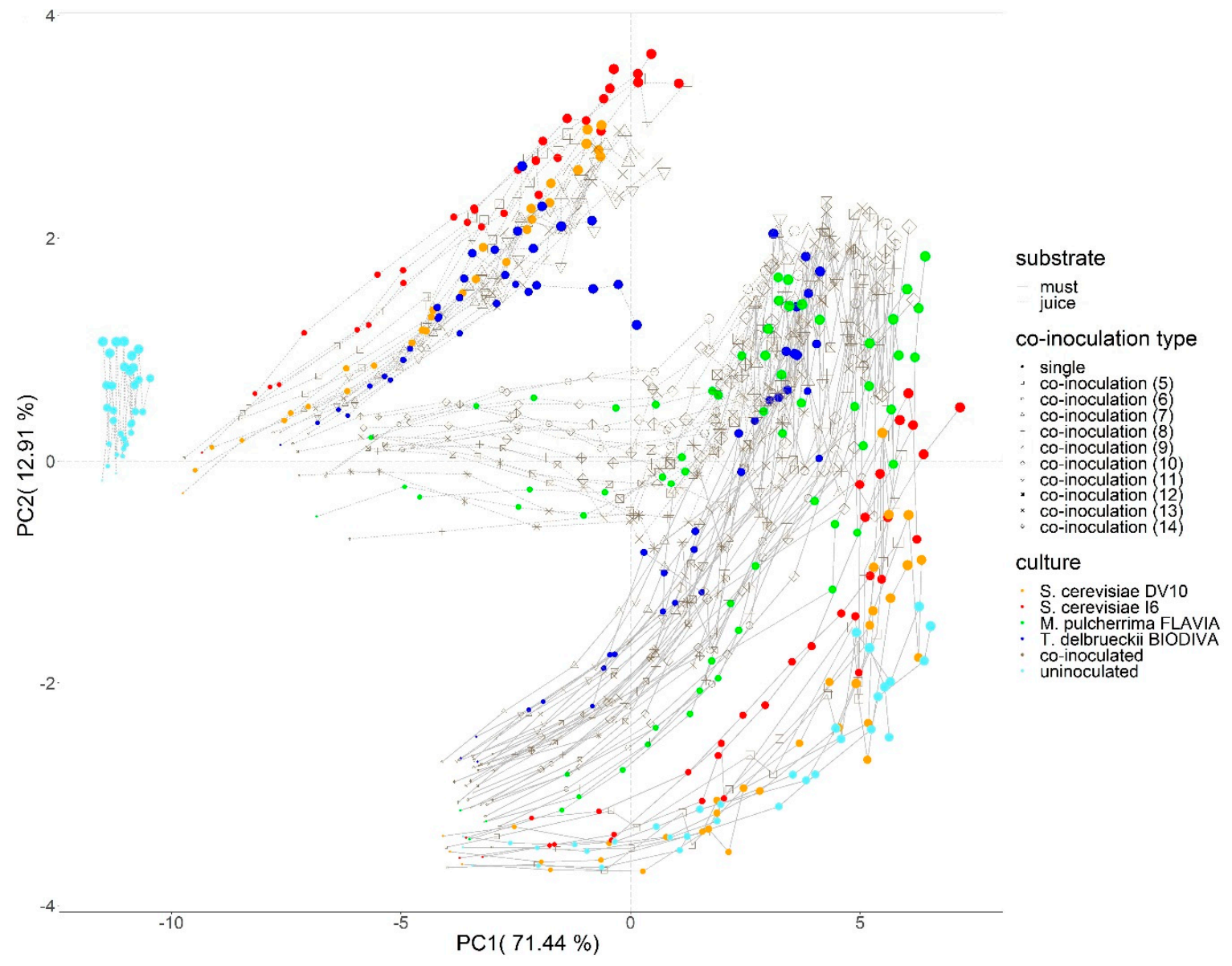

Figure 2. Score plot of the principal component analysis of volatile organic compound (VOC) emission evolution associated with the first three days of AF for each trial tested in this study. Data were logarithmically transformed and centered. Different colors indicate the different yeast managements, medium, and blank samples. The size of the points grew with the time of measurements. For a detailed view of the figure, the original image is included in the Supplementary Materials (Figure S1). 
Separations and different evolutions were evident by comparing the matrices 'grape must' and 'grape juice'. In the 'must' assays, it was clear the partition between the trials with only $S$. cerevisiae strains inoculated (sample codes 1, 2, and 5; Table 1) and those that included, in the starter cultures, non-Saccharomyces strains (sample codes 3, and 4; Table 1) (Figure 2). Additionally, a diverse behavior was noticeable for the fermentations inoculated with pure cultures of $M$. pulcherrima FLAVIA and T. delbrueckii BIODIVA strains, respectively. All the experiments that included both S. cerevisiae and non-Saccharomyces strains (sample codes 6-14; Table 1) followed a trend that appeared more similar to the non-Saccharomyces pure cultures. Concerning the 'juice' experimental plan, an uniform trend was confirmed for the samples inoculated with the S. cerevisiae strains (Figure 2). In contrast, the behavior observed for the pure inoculation of M. pulcherrima FLAVIA strain (sample code 3; Table 1) was radically different. The pure culture of T. delbrueckii BIODIVA strain (sample code 4; Table 1) and all the combinations of S. cerevisiae-T. delbrueckii (sample codes 7, 9, and 11; Table 1) followed trajectories closer to those of $S$. cerevisiae strains than to the $M$. pulcherrima one. In contrast, all the other trials (sample codes 6, 8, 10, and 12-14; Table 1) observed patterns of evolution similar to M. pulcherrima. Concerning these last trials, some samples also included T. delbrueckii BIODIVA among the inoculated strains. In the case of PCA, the loading plot (Figure 3) indicates the mass peaks related to the observed evolution of the VOC profile in Figure 2.

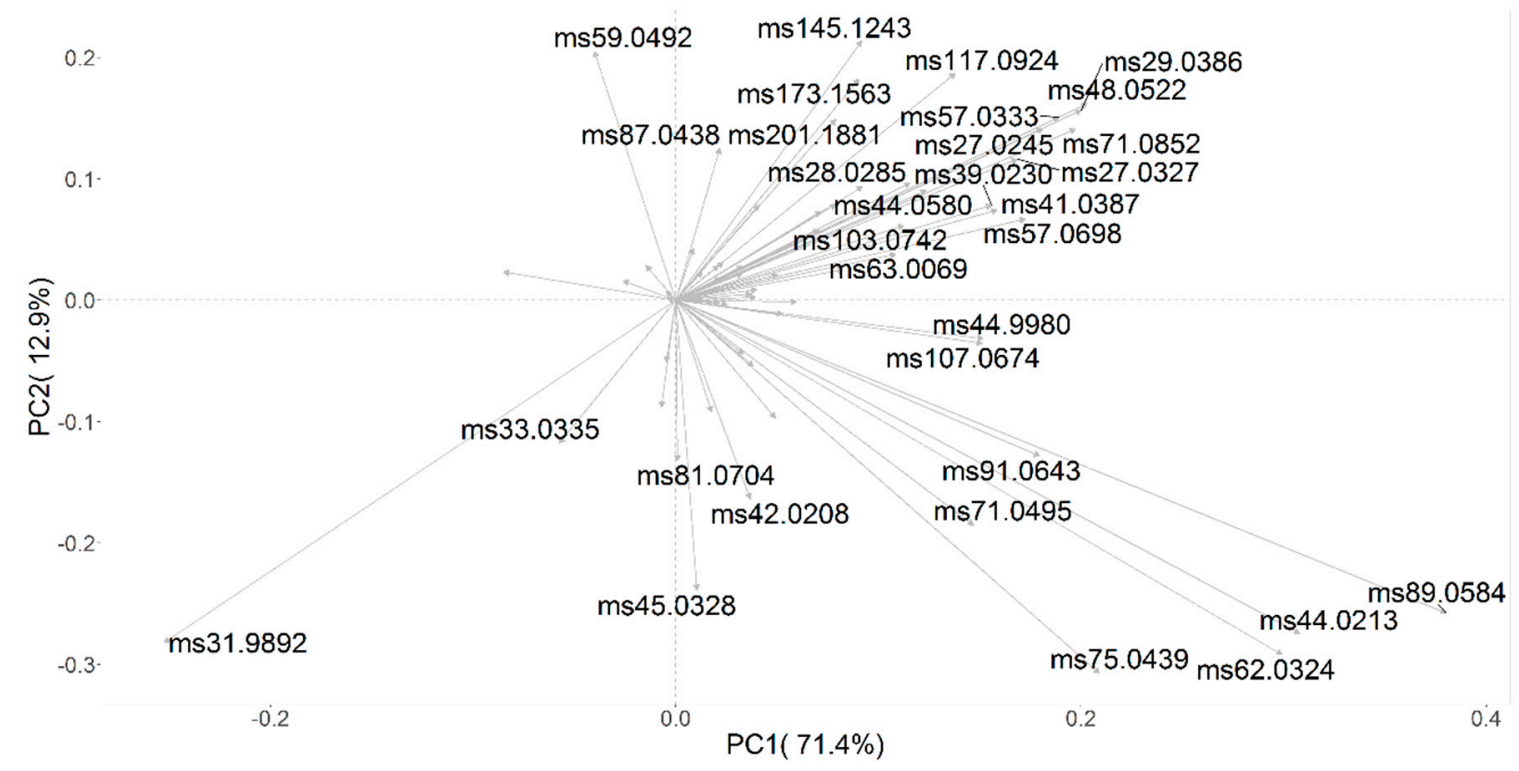

Figure 3. Loading plot of principal component analysis of the mass peaks (ms) related to the observed evolution of VOCs profile in Figure 2. For a detailed view of the figure, the original image is included in the Supplementary Materials (Figure S2).

More than 70 mass peaks were identified among the four yeast commercial starters during online monitoring throughout the three days of fermentation. For each of these mass peaks, it was possible to perform a tentative identification (allowing a possible link of the ion with a given molecule/molecular fragment) and to follow the evolution of the intensity in the time, allowing a direct analytic determination to evaluate the yeast metabolic activity during the progress of AF.

More specifically, differences between the matrices used were observed when the score plot of the PCA analysis on the distribution of variances associated with VOC emission during the first three days of AF was represented separately for each trial (Figure 4). Negligible VOC evolution was evident in uninoculated grape juice and slow evolution in grape must as revealed by the first PCA dimension, which is related to the increase of volatile concentration in the sample headspace (Figure 4, uninoculated trial, experiment 15). Regarding the inoculated yeasts, differences in the VOC emissions were also found. For example, M. pulcherrima and T. delbrueckii in single culture (Figure 4, experiments 
3 and 4) tended to reach a lesser concentration of VOCs in juice, while both S. cerevisiae kept producing more volatile compounds with time (Figure 4, experiments 1 and 2). Moreover, this graph confirmed that there were differences between the different yeast combinations inoculated, as they were arranged in the graph according to different patterns. This effect is of particular interest, if we consider that together with the effect of different strains/species combinations we also tested the impact of the increasing microbial diversity of the starter cultures inoculated.

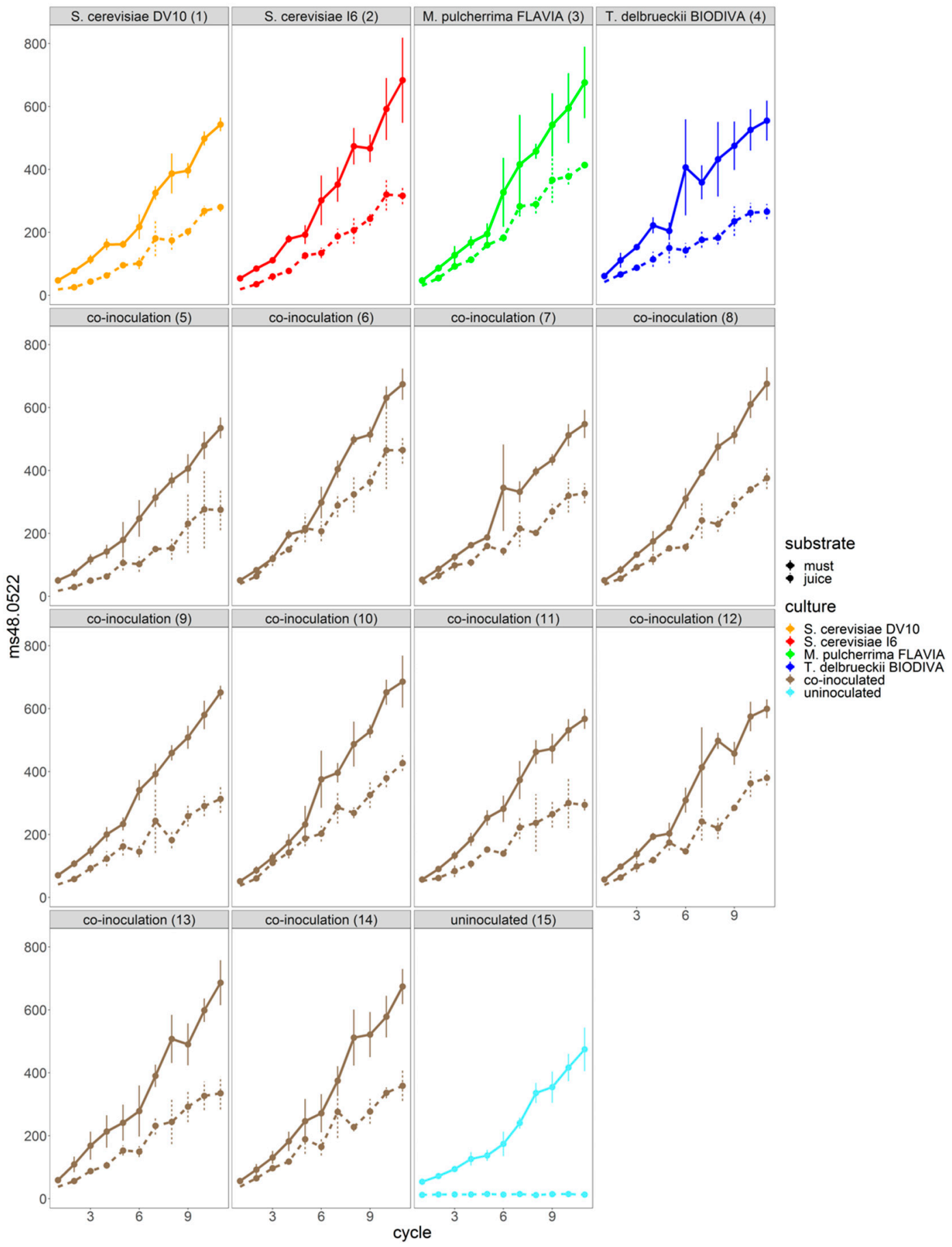

Figure 4. Score plot of principal component analysis of VOC emission evolution associated with the first three days of AF, separately represented for each trial (Table 1). Continuous lines indicate grape must and broken lines indicate grape juice. For a detailed view of the figure, the original image is included in the Supplementary Materials (Figure S3). 


\section{Discussion}

Wine is a peculiar commodity in the agrifood sector in terms of business opportunities and innovative trends [47]. The management of AF deeply affects the optimization of the product quality and the improvement of process sustainability [48-52]. Several variables can influence the performance of AF such as grape variety, yeast species, yeast strain, nutrient availability for the yeasts, temperature of the process, addition of chemical compounds, and technological regimen [49,53-55]. The fact that these variables are often intimately connected leads to a huge 'oenological space' that needs to be explored. This observation explains the high interest in approaches tested to monitor this bioprocess [53,56] including those using VOCs as target molecules [57-61]. Furthermore, it is important to underline that the study of VOC diversity has a dual significance; on one hand, VOC variability is the effect of yeast metabolism, on the other, VOCs represent the molecular basis of the sensory perception of wine tasting $[1,62,63]$. Among the DIMS techniques, no study has delved into the survey of the untargeted diversity of volatiles associated with the wine headspace in order to (i) monitor online the progress of $\mathrm{AF}$, and (ii) evaluate the impact of the different variables of wine quality [4].

As a case study, the assessment of VOCs variability associated with different combinations of Saccharomyces/non-Saccharomyces was selected. In fermented beverages such as wine, a relevant field of study deals with the contribution of microbiological resources to the organoleptic and sensory properties of the final product $[64,65]$. In the winemaking process, some of the most characteristic flavor and aroma components are synthesized by yeasts during the AF [66]. S. cerevisiae is the main responsible microorganism of the AF in wine, but nowadays, non-Saccharomyces yeasts are used in industry to improve flavor, aroma, and stability $[16,22,64,65]$. This heterogeneous class of eukaryotic microorganisms detains a wide enzymatic diversity [67-69]. In this light, it appears comprehensible the interest in the formation of volatile compounds by both Saccharomyces and non-Saccharomyces yeasts, which are important to maximize the sensorial quality of the final products. The present study, in particular, tested the PTR-ToF-MS-based approach recently optimized to compare the performance of different yeasts in cultural media [35]. This technology has been successfully employed in fermented foods and beverages to monitor the effect of different microorganisms responsible for the fermentative process, for instance, to discriminate wines inoculated with different malolactic starters [39], monitor lactic fermentation driven by different yoghurt commercial starter cultures [33], and characterize single commercial yeast starters in bread productions [36]. This study proposed the first application of PTR-ToF-MS for the AF monitoring in wine, demonstrating the high potential of this analytical approach to explore the huge number of variables influencing this bioprocess crucial in winemaking.

Concerning the yeast population kinetics, the respective inoculation of non-Saccaromyces and Saccharomyces strains to promote/drive alcoholic fermentation in wine were generally performed (i) by inoculating together the strains (generally with a ratio 100:1 in favor of the non-Saccharomyces strain) (simultaneous inoculation) or (ii) inoculating the Saccharomyces strain with a delay of 24-48 h compared to the non-Saccharomyces inoculation (sequential inoculation) [70-72]. Both approaches aimed to maximize the development of non-Saccharomyces, concretizing an advantage for these yeasts [73]. The oenological objective is to counteract the fermentative advantage of S. cerevisiae, allowing non-Saccharomyces yeasts to influence wine quality [74]. The findings reported in the present article suggest that simultaneous inoculation led to good growth/survival for the tested non-Saccharomyces in combination with the selected S. cerevisiae strain. Cell concentration remained particularly high for T. delbrueckii, confirming the ability of this non-Saccharomyces yeast to survive at high ethanol concentrations [75]. For M. pulcherrima, the evidence was only partially in accordance to that reported by Dutraive et al. [17], who observed an initial decline of this yeast between the second and the third day after the inoculation, but followed by the complete annulment of the population.

The analysis included both commercial grape juice and fresh grape must to test the efficacy of the technique both in model conditions and in the real winemaking conditions. In fact, commercial grape juice, together with synthetic grape must [76] represents a common model medium for the fermentative studies in oenology (e.g., $[77,78])$. We found an evolution of volatiles during the three days of the study, 
which was in accordance with the evolution of yeast cell counts carried out during the AF. The results reported from the analysis of 'volatomes' associated with the development of single yeast species depicted different trends that could be coherent with different claimed aromatic properties for three commercialized strains, which received a considerable interest in the scientific literature (S. cerevisiae DV10, e.g., [79-83]; M. pulcherrima FLAVIA, e.g., [17,19,84-87]; T. delbrueckii BIODIVA, e.g., [17,84-88]). The study highlighted a global separation of VOC variability associated with the headspaces of the two tested matrices that can be ascribable to the chemical differences and/or to variable microbiological properties of the two media. Interesting, the behavior VOCs released by M. pulcherrima FLAVIA radically changed, shifting from fresh must to commercial juice, meaning that chemical/microbiological determinants of these media can directly or indirectly modulate VOC production by the yeasts. Even if the effect of abiotic and biotic interaction in the wine environment have been extensively investigated [89-91], further studies are needed to understand the biology affecting this phenotype, particularly in light of the huge intraspecific variability in terms of oenological properties within the species M. pulcherrima [92]. Intriguingly, variable patterns in must versus juice have also been observed in the trials where M. pulcherrima was co-inoculated with S. cerevisiae and with T. delbrueckii. A few studies have delved into the compatibility of $S$. cerevisiae combined in the same vinification with more than one non-Saccharomyces species $[69,93]$. Except for the coupled Lachancea thermotolerans and Schizosaccharomyces pombe that (used both in combination but not with also S. cerevisiae) has been extensively explored [94-96], only one study has tested the sensory impact (but not the VOC analysis) of this non-Saccharomyces multiple inoculation in wine [69]. In fact, usually, the articles considered the impact on volatile diversity of single strains or mixed starters composed of one S. cerevisiae strain and one non-Saccharomyces species. While the effect of multiple Saccharomyces yeast co-inoculations on volatile wine composition has been assessed (yeast inocula differed substantially in volatile thiols and other flavor compounds) $[97,98]$, the interactions among different non-Saccharomyces wine yeast species need to be further elucidated [69]. The present findings suggest that the addition of M. pulcherrima to the coupled (in the case of the strains we tested) S. cerevisiae/T. delbrueckii can modify the global release of volatiles during the AF in wine as a function of the fermented matrix.

The different behaviors of the 'volatomes' associated with the single and mixed cultures showed promising results in terms of variability of the single mass peaks. The study of individual peak mass profiles during the three first days of AF in association with the tested yeast combinations will be the natural follow-up of the present communication. The objective will be focused to elucidate the single mass peaks/molecules responsible for the strain/species-specific differences and the specific yeast interactions/combinations, but also for the selection of candidate 'volatile' markers for the rapid screening of new microbial resources for 'flavoring' starter culture design in wine fermentations. Some findings have corroborated the evidence that the complexity of the microbial starter cultures inoculated can be among the levers capable of improving sensory wine complexity, assuring the safety of the productions (also for the possible exploitation in terms of biocontrol activity) [12,99-101]. It is interesting to underline that the tested strategy could find an application also in testing the interaction of yeast with malolactic bacteria [102-105]. Furthermore, it is important to stress how the proposed exploration of the phenotypic space of yeast activity in oenology can open new research lines for fundamental research in the field of yeast biology [106-108].

\section{Conclusions}

PTR-ToF-MS, combining high sensitivity/accuracy without neither sample preparation nor sample destruction, allows rapid real-time determination of volatile organic compounds (VOCs). In this paper, preliminary findings on the application of this analytical approach for the online monitoring of alcoholic fermentation in wine is proposed. The study explored different single and multiple inoculation of diverse oenological yeasts both in commercial grape juice and fresh must. The experiment highlighted a variability of the global volatiles in association with (i) the different yeast species, (ii) the different yeast combinations, and (iii) the different fermenting matrices. The evidence demonstrates the potential 
of PTR-ToF-MS in monitoring experimental variables associated with alcoholic fermentation in wine, opening new opportunities to manage this crucial phase, thus improving the quality of the final products and optimizing the processes.

Supplementary Materials: The following are available online at http://www.mdpi.com/2311-5637/6/2/55/s1, Figure S1: source file for Figure 2. Figure S2: source file for Figure 3. Figure S3: source file for Figure 4.

Author Contributions: Conceptualization, C.B., I.K., P.R., G.S., M.F., F.B., and V.C.; Methodology, C.B., I.K., P.R., G.S., M.F., F.B., and V.C.; Investigation, C.B., I.K., P.R., M.F., F.B., and V.C.; Resources, G.S., F.B., and V.C.; Data curation, C.B., I.K., F.B., and V.C.; Writing-original draft preparation, C.B., I.K., and V.C.; Writing-review and editing, P.R., G.S., M.F., and F.B.; Supervision, G.S. and F.B.; Project administration, F.B. and V.C.; Funding acquisition, F.B. and V.C. All authors have read and agreed to the published version of the manuscript.

Funding: Pasquale Russo is the beneficiary of a grant by MIUR in the framework of 'AIM: Attraction and International Mobility' (PON R\&I 2014-2020) (practice code D74I18000190001). The work has been partially supported by the Autonomous Province of Trento (ADP 2020).

Acknowledgments: We would like to thank (i) the three anonymous reviewers for their suggestions and comments, (ii) Francesco De Marzo and Massimo Franchi of the Institute of Sciences of Food Production-CNR for their skilled technical support provided during the realization of this work, and (iii) Sergio Pelosi of the Institute of Sciences of Food Production-CNR for their critical reading of the manuscript.

Conflicts of Interest: The authors declare no conflicts of interest.

\section{References}

1. Belda, I.; Ruiz, J.; Esteban-Fernández, A.; Navascués, E.; Marquina, D.; Santos, A.; Moreno-Arribas, M.V. Microbial Contribution to Wine Aroma and Its Intended Use for Wine Quality Improvement. Mol. Basel Switz. 2017, 22, 189. [CrossRef] [PubMed]

2. Benito, Á.; Calderón, F.; Benito, S. The Influence of Non-Saccharomyces Species on Wine Fermentation Quality Parameters. Fermentation 2019, 5, 54. [CrossRef]

3. Lebrón-Aguilar, R.; Soria, A.C.; Quintanilla-López, J.E. Comprehensive evaluation of direct injection mass spectrometry for the quantitative profiling of volatiles in food samples. Philos. Trans. R. Soc. Math. Phys. Eng. Sci. 2016, 374, 20150375. [CrossRef]

4. Pinu, F.R. Grape and Wine Metabolomics to Develop New Insights Using Untargeted and Targeted Approaches. Fermentation 2018, 4, 92. [CrossRef]

5. Tufariello, M.; Maiorano, G.; Rampino, P.; Spano, G.; Grieco, F.; Perrotta, C.; Capozzi, V.; Grieco, F. Selection of an autochthonous yeast starter culture for industrial production of Primitivo "Gioia del Colle" PDO/DOC in Apulia (Southern Italy). LWT 2019, 99, 188-196. [CrossRef]

6. Garofalo, C.; Tristezza, M.; Grieco, F.; Spano, G.; Capozzi, V. From grape berries to wine: Population dynamics of cultivable yeasts associated to "Nero di Troia" autochthonous grape cultivar. World J. Microbiol. Biotechnol. 2016, 32, 59. [CrossRef]

7. Capozzi, V.; Garofalo, C.; Chiriatti, M.A.; Grieco, F.; Spano, G. Microbial terroir and food innovation: The case of yeast biodiversity in wine. Microbiol. Res. 2015, 181, 75-83. [CrossRef] [PubMed]

8. Ciani, M.; Comitini, F.; Mannazzu, I.; Domizio, P. Controlled mixed culture fermentation: A new perspective on the use of non-Saccharomyces yeasts in winemaking. FEMS Yeast Res. 2010, 10, 123-133. [CrossRef] [PubMed]

9. Comitini, F.; Gobbi, M.; Domizio, P.; Romani, C.; Lencioni, L.; Mannazzu, I.; Ciani, M. Selected non-Saccharomyces wine yeasts in controlled multistarter fermentations with Saccharomyces cerevisiae. Food Microbiol. 2011, 28, 873-882. [CrossRef]

10. Tronchoni, J.; Curiel, J.A.; Morales, P.; Torres-Pérez, R.; Gonzalez, R. Early transcriptional response to biotic stress in mixed starter fermentations involving Saccharomyces cerevisiae and Torulaspora delbrueckii. Int. J. Food Microbiol. 2017, 241, 60-68. [CrossRef]

11. Ciani, M.; Morales, P.; Comitini, F.; Tronchoni, J.; Canonico, L.; Curiel, J.A.; Oro, L.; Rodrigues, A.J.; Gonzalez, R. Non-conventional Yeast Species for Lowering Ethanol Content of Wines. Front. Microbiol. 2016, 7, 642. [CrossRef] [PubMed]

12. Rossouw, D.; Bauer, F.F. Exploring the phenotypic space of non-Saccharomyces wine yeast biodiversity. Food Microbiol. 2016, 55, 32-46. [CrossRef] [PubMed] 
13. Beckner Whitener, M.E.; Stanstrup, J.; Panzeri, V.; Carlin, S.; Divol, B.; Du Toit, M.; Vrhovsek, U. Untangling the wine metabolome by combining untargeted SPME-GCxGC-TOF-MS and sensory analysis to profile Sauvignon blanc co-fermented with seven different yeasts. Metabolomics 2016, 12, 53. [CrossRef]

14. Lu, Y.; Huang, D.; Lee, P.R.; Liu, S.Q. Assessment of volatile and non-volatile compounds in durian wines fermented with four commercial non-Saccharomyces yeasts. J. Sci. Food Agric. 2016, 96, 1511-1521. [CrossRef]

15. Medina, K.; Boido, E.; Dellacassa, E.; Carrau, F. Growth of non-Saccharomyces yeasts affects nutrient availability for Saccharomyces cerevisiae during wine fermentation. Int. J. Food Microbiol. 2012, 157, 245-250. [CrossRef]

16. Petruzzi, L.; Capozzi, V.; Berbegal, C.; Corbo, M.R.; Bevilacqua, A.; Spano, G.; Sinigaglia, M. Microbial Resources and Enological Significance: Opportunities and Benefits. Front. Microbiol. 2017, 8, 995. [CrossRef]

17. Dutraive, O.; Benito, S.; Fritsch, S.; Beisert, B.; Patz, C.D.; Rauhut, D. Effect of Sequential Inoculation with Non-Saccharomyces and Saccharomyces Yeasts on Riesling Wine Chemical Composition. Fermentation 2019, 5 , 79. [CrossRef]

18. Du Plessis, H.; Du Toit, M.; Nieuwoudt, H.; Van der Rijst, M.; Hoff, J.; Jolly, N. Modulation of Wine Flavor using Hanseniaspora uvarum in Combination with Different Saccharomyces cerevisiae, Lactic Acid Bacteria Strains and Malolactic Fermentation Strategies. Fermentation 2019, 5, 64. [CrossRef]

19. Morata, A.; Loira, I.; Escott, C.; del Fresno, J.M.; Bañuelos, M.A.; Suárez-Lepe, J.A. Applications of Metschnikowia pulcherrima in Wine Biotechnology. Fermentation 2019, 5, 63. [CrossRef]

20. Garofalo, C.; Russo, P.; Beneduce, L.; Massa, S.; Spano, G.; Capozzi, V. Non-Saccharomyces biodiversity in wine and the 'microbial terroir': A survey on Nero di Troia wine from the Apulian region, Italy. Ann. Microbiol. 2016, 66, 143-150. [CrossRef]

21. Sgouros, G.; Chalvantzi, I.; Mallouchos, A.; Paraskevopoulos, Y.; Banilas, G.; Nisiotou, A. Biodiversity and Enological Potential of Non-Saccharomyces Yeasts from Nemean Vineyards. Fermentation 2018, 4, 32. [CrossRef]

22. Roudil, L.; Russo, P.; Berbegal, C.; Albertin, W.; Spano, G.; Capozzi, V. Non-Saccharomyces Commercial Starter Cultures: Scientific Trends, Recent Patents and Innovation in the Wine Sector. Recent Pat. Food Nutr. Agric. 2019. [CrossRef] [PubMed]

23. Lindinger, W.; Jordan, A. Proton-transfer-reaction mass spectrometry (PTR-MS): On-line monitoring of volatile organic compounds at pptv levels. Chem. Soc. Rev. 1998, 27, 347-375. [CrossRef]

24. Jordan, A.; Haidacher, S.; Hanel, G.; Hartungen, E.; Märk, L.; Seehauser, H.; Schottkowsky, R.; Sulzer, P.; Märk, T.D. A high resolution and high sensitivity proton-transfer-reaction time-of-flight mass spectrometer (PTR-TOF-MS). Int. J. Mass Spectrom. 2009, 286, 122-128. [CrossRef]

25. Capozzi, V.; Yener, S.; Khomenko, I.; Farneti, B.; Cappellin, L.; Gasperi, F.; Scampicchio, M.; Biasioli, F. PTR-ToF-MS Coupled with an Automated Sampling System and Tailored Data Analysis for Food Studies: Bioprocess Monitoring, Screening and Nose-space Analysis. JoVE J. Vis. Exp. 2017, e54075. [CrossRef]

26. Cappellin, L.; Loreto, F.; Aprea, E.; Romano, A.; Del Pulgar, J.S.; Gasperi, F.; Biasioli, F. PTR-MS in Italy: A Multipurpose Sensor with Applications in Environmental, Agri-Food and Health Science. Sensors 2013, 13, 11923-11955. [CrossRef]

27. Pico, J.; Khomenko, I.; Capozzi, V.; Navarini, L.; Bernal, J.; Gómez, M.; Biasioli, F. Analysis of volatile organic compounds in crumb and crust of different baked and toasted gluten-free breads by direct PTR-ToF-MS and fast-GC-PTR-ToF-MS. J. Mass Spectrom. 2018, 53, 893-902. [CrossRef]

28. Deuscher, Z.; Andriot, I.; Sémon, E.; Repoux, M.; Preys, S.; Roger, J.M.; Boulanger, R.; Labouré, H.; Quéré, J.L.L. Volatile compounds profiling by using proton transfer reaction-time of flight-mass spectrometry (PTR-ToF-MS). The case study of dark chocolates organoleptic differences. J. Mass Spectrom. 2019, 54, 92-119. [CrossRef]

29. van Ruth, S.M.; Koot, A.; Akkermans, W.; Araghipour, N.; Rozijn, M.; Baltussen, M.; Wisthaler, A.; Märk, T.D.; Frankhuizen, R. Butter and butter oil classification by PTR-MS. Eur. Food Res. Technol. 2008, 227, 307-317. [CrossRef]

30. Capozzi, V.; Lonzarich, V.; Khomenko, I.; Cappellin, L.; Navarini, L.; Biasioli, F. Unveiling the Molecular Basis of Mascarpone Cheese Aroma: VOCs analysis by SPME-GC/MS and PTR-ToF-MS. Molecules 2020, 25, 1242. [CrossRef] 
31. Makhoul, S.; Yener, S.; Khomenko, I.; Capozzi, V.; Cappellin, L.; Aprea, E.; Scampicchio, M.; Gasperi, F.; Biasioli, F. Rapid non-invasive quality control of semi-finished products for the food industry by direct injection mass spectrometry headspace analysis: The case of milk powder, whey powder and anhydrous milk fat. J. Mass Spectrom. 2016, 51, 782-791. [CrossRef] [PubMed]

32. Romano, A.; Capozzi, V.; Spano, G.; Biasioli, F. Proton transfer reaction-mass spectrometry: Online and rapid determination of volatile organic compounds of microbial origin. Appl. Microbiol. Biotechnol. 2015, 99, 3787-3795. [CrossRef] [PubMed]

33. Benozzi, E.; Romano, A.; Capozzi, V.; Makhoul, S.; Cappellin, L.; Khomenko, I.; Aprea, E.; Scampicchio, M.; Spano, G.; Märk, T.D.; et al. Monitoring of lactic fermentation driven by different starter cultures via direct injection mass spectrometric analysis of flavour-related volatile compounds. Food Res. Int. 2015, 76, 682-688. [CrossRef] [PubMed]

34. Richter, T.M.; Silcock, P.; Algarra, A.; Eyres, G.T.; Capozzi, V.; Bremer, P.J.; Biasioli, F. Evaluation of PTR-ToF-MS as a tool to track the behavior of hop-derived compounds during the fermentation of beer. Food Res. Int. 2018, 111, 582-589. [CrossRef] [PubMed]

35. Khomenko, I.; Stefanini, I.; Cappellin, L.; Cappelletti, V.; Franceschi, P.; Cavalieri, D.; Märk, T.D.; Biasioli, F. Non-invasive real time monitoring of yeast volatilome by PTR-ToF-MS. Metab. Off. J. Metab. Soc. 2017, 13, 118. [CrossRef]

36. Capozzi, V.; Makhoul, S.; Aprea, E.; Romano, A.; Cappellin, L.; Sanchez Jimena, A.; Spano, G.; Gasperi, F.; Scampicchio, M.; Biasioli, F. PTR-MS Characterization of VOCs Associated with Commercial Aromatic Bakery Yeasts of Wine and Beer Origin. Molecules 2016, 21, 483. [CrossRef]

37. Makhoul, S.; Romano, A.; Capozzi, V.; Spano, G.; Aprea, E.; Cappellin, L.; Benozzi, E.; Scampicchio, M.; Märk, T.D.; Gasperi, F.; et al. Volatile Compound Production During the Bread-Making Process: Effect of Flour, Yeast and Their Interaction. Food Bioprocess Technol. 2015, 8, 1925-1937. [CrossRef]

38. Makhoul, S.; Romano, A.; Cappellin, L.; Spano, G.; Capozzi, V.; Benozzi, E.; Märk, T.D.; Aprea, E.; Gasperi, F.; El-Nakat, H.; et al. Proton-transfer-reaction mass spectrometry for the study of the production of volatile compounds by bakery yeast starters. J. Mass Spectrom. JMS 2014, 49, 850-859. [CrossRef]

39. Campbell-Sills, H.; Capozzi, V.; Romano, A.; Cappellin, L.; Spano, G.; Breniaux, M.; Lucas, P.; Biasioli, F. Advances in wine analysis by PTR-ToF-MS: Optimization of the method and discrimination of wines from different geographical origins and fermented with different malolactic starters. Int. J. Mass Spectrom. 2016, 397-398, 42-51. [CrossRef]

40. Romano, A.; Fischer, L.; Herbig, J.; Campbell-Sills, H.; Coulon, J.; Lucas, P.; Cappellin, L.; Biasioli, F. Wine analysis by FastGC proton-transfer reaction-time-of-flight-mass spectrometry. Int. J. Mass Spectrom. 2014, 369, 81-86. [CrossRef]

41. Sémon, E.; Arvisenet, G.; Guichard, E.; Quéré, J.L.L. Modified proton transfer reaction mass spectrometry (PTR-MS) operating conditions for in vitro and in vivo analysis of wine aroma. J. Mass Spectrom. 2018, 53, 65-77. [CrossRef] [PubMed]

42. Muñoz-González, C.; Canon, F.; Feron, G.; Guichard, E.; Pozo-Bayón, M.A. Assessment Wine Aroma Persistence by Using an in Vivo PTR-ToF-MS Approach and Its Relationship with Salivary Parameters. Mol. Basel Switz. 2019, 24, 1277. [CrossRef] [PubMed]

43. Garofalo, C.; El Khoury, M.; Lucas, P.; Bely, M.; Russo, P.; Spano, G.; Capozzi, V. Autochthonous starter cultures and indigenous grape variety for regional wine production. J. Appl. Microbiol. 2015, 118, 1395-1408. [CrossRef] [PubMed]

44. Cappellin, L.; Biasioli, F.; Fabris, A.; Schuhfried, E.; Soukoulis, C.; Märk, T.D.; Gasperi, F. Improved mass accuracy in PTR-TOF-MS: Another step towards better compound identification in PTR-MS. Int. J. Mass Spectrom. 2010, 290, 60-63. [CrossRef]

45. Cappellin, L.; Biasioli, F.; Granitto, P.M.; Schuhfried, E.; Soukoulis, C.; Costa, F.; Märk, T.D.; Gasperi, F. On data analysis in PTR-TOF-MS: From raw spectra to data mining. Sens. Actuators B Chem. 2011, 155, 183-190. [CrossRef]

46. Lindinger, W.; Hansel, A.; Jordan, A. On-line monitoring of volatile organic compounds at pptv levels by means of proton-transfer-reaction mass spectrometry (PTR-MS) medical applications, food control and environmental research. Int. J. Mass Spectrom. Ion Process. 1998, 173, 191-241. [CrossRef]

47. Bisson, L.F.; Waterhouse, A.L.; Ebeler, S.E.; Walker, M.A.; Lapsley, J.T. The present and future of the international wine industry. Nature 2002, 418, 696-699. [CrossRef] 
48. Berbegal, C.; Fragasso, M.; Russo, P.; Bimbo, F.; Grieco, F.; Spano, G.; Capozzi, V. Climate Changes and Food Quality: The Potential of Microbial Activities as Mitigating Strategies in the Wine Sector. Fermentation 2019, 5, 85. [CrossRef]

49. Bisson, L.F. Stuck and Sluggish Fermentations. Am. J. Enol. Vitic. 1999, 50, 107-119.

50. Fleet, G.H. Wine yeasts for the future. FEMS Yeast Res. 2008, 8, 979-995. [CrossRef]

51. Pretorius, I.S. Tailoring wine yeast for the new millennium: Novel approaches to the ancient art of winemaking. Yeast 2000, 16, 675-729. [CrossRef]

52. Nardi, T. Microbial Resources as a Tool for Enhancing Sustainability in Winemaking. Microorganisms 2020, 8 , 507. [CrossRef]

53. Sablayrolles, J.M. Control of alcoholic fermentation in winemaking: Current situation and prospect. Food Res. Int. 2009, 42, 418-424. [CrossRef]

54. Molina, A.M.; Swiegers, J.H.; Varela, C.; Pretorius, I.S.; Agosin, E. Influence of wine fermentation temperature on the synthesis of yeast-derived volatile aroma compounds. Appl. Microbiol. Biotechnol. 2007, 77, 675-687. [CrossRef] [PubMed]

55. Russo, P.; Berbegal, C.; De Ceglie, C.; Grieco, F.; Spano, G.; Capozzi, V. Pesticide Residues and Stuck Fermentation in Wine: New Evidences Indicate the Urgent Need of Tailored Regulations. Fermentation 2019, 5, 23. [CrossRef]

56. Di Egidio, V.; Sinelli, N.; Giovanelli, G.; Moles, A.; Casiraghi, E. NIR and MIR spectroscopy as rapid methods to monitor red wine fermentation. Eur. Food Res. Technol. 2010, 230, 947-955. [CrossRef]

57. Mouret, J.R.; Perez, M.; Angenieux, M.; Nicolle, P.; Farines, V.; Sablayrolles, J.M. Online-Based Kinetic Analysis of Higher Alcohol and Ester Synthesis During Winemaking Fermentations. Food Bioprocess Technol. 2014, 7, 1235-1245. [CrossRef]

58. Mallouchos, A.; Komaitis, M.; Koutinas, A.; Kanellaki, M. Investigation of Volatiles Evolution during the Alcoholic Fermentation of Grape Must Using Free and Immobilized Cells with the Help of Solid Phase Microextraction (SPME) Headspace Sampling. J. Agric. Food Chem. 2002, 50, 3840-3848. [CrossRef]

59. Morales, M.L.; Fierro-Risco, J.; Callejón, R.M.; Paneque, P. Monitoring volatile compounds production throughout fermentation by Saccharomyces and non-Saccharomyces strains using headspace sorptive extraction. J. Food Sci. Technol. 2017, 54, 538-557. [CrossRef]

60. Silva Ferreira, A.C.; Monforte, A.R.; Teixeira, C.S.; Martins, R.; Fairbairn, S.; Bauer, F.F. Monitoring Alcoholic Fermentation: An Untargeted Approach. J. Agric. Food Chem. 2014, 62, 6784-6793. [CrossRef]

61. Buratti, S.; Benedetti, S. Chapter 28-Alcoholic Fermentation Using Electronic Nose and Electronic Tongue. In Electronic Noses and Tongues in Food Science; Rodríguez Méndez, M.L., Ed.; Academic Press: San Diego, CA, USA, 2016; pp. 291-299, ISBN 978-0-12-800243-8.

62. Aguilera, T.; Lozano, J.; Paredes, J.A.; Álvarez, F.J.; Suárez, J.I. Electronic Nose Based on Independent Component Analysis Combined with Partial Least Squares and Artificial Neural Networks for Wine Prediction. Sensors 2012, 12, 8055-8072. [CrossRef] [PubMed]

63. Jiang, B.; Zhang, Z. Volatile Compounds of Young Wines from Cabernet Sauvignon, Cabernet Gernischet and Chardonnay Varieties Grown in the Loess Plateau Region of China. Molecules 2010, 15, 9184-9196. [CrossRef] [PubMed]

64. Jolly, N.P.; Varela, C.; Pretorius, I.S. Not your ordinary yeast: Non-Saccharomyces yeasts in wine production uncovered. FEMS Yeast Res. 2014, 14, 215-237. [CrossRef] [PubMed]

65. Berbegal, C.; Spano, G.; Tristezza, M.; Grieco, F.; Capozzi, V. Microbial Resources and Innovation in the Wine Production Sector. S. Afr. J. Enol. Vitic. 2017, 38, 156-166. [CrossRef]

66. Lambrechts, M.G.; Pretorius, I.S. Yeast and its Importance to Wine Aroma-A Review. S. Afr. J. Enol. Vitic. 2000, 21, 97-129. [CrossRef]

67. Escribano, R.; González-Arenzana, L.; Garijo, P.; Berlanas, C.; López-Alfaro, I.; López, R.; Gutiérrez, A.R.; Santamaría, P. Screening of enzymatic activities within different enological non-Saccharomyces yeasts. J. Food Sci. Technol. 2017, 54, 1555-1564. [CrossRef]

68. Escribano, R.; González-Arenzana, L.; Portu, J.; Garijo, P.; López-Alfaro, I.; López, R.; Santamaría, P.; Gutiérrez, A.R. Wine aromatic compound production and fermentative behaviour within different non-Saccharomyces species and clones. J. Appl. Microbiol. 2018, 124, 1521-1531. [CrossRef] 
69. Padilla, B.; Gil, J.V.; Manzanares, P. Past and Future of Non-Saccharomyces Yeasts: From Spoilage Microorganisms to Biotechnological Tools for Improving Wine Aroma Complexity. Front. Microbiol. 2016, 7, 411. [CrossRef]

70. Ciani, M.; Beco, L.; Comitini, F. Fermentation behaviour and metabolic interactions of multistarter wine yeast fermentations. Int. J. Food Microbiol. 2006, 108, 239-245. [CrossRef]

71. Taillandier, P.; Lai, Q.P.; Julien-Ortiz, A.; Brandam, C. Interactions between Torulaspora delbrueckii and Saccharomyces cerevisiae in wine fermentation: Influence of inoculation and nitrogen content. World J. Microbiol. Biotechnol. 2014, 30, 1959-1967. [CrossRef]

72. Contreras, A.; Hidalgo, C.; Henschke, P.A.; Chambers, P.J.; Curtin, C.; Varela, C. Evaluation of Non-Saccharomyces Yeasts for the Reduction of Alcohol Content in Wine. Appl. Environ. Microbiol. 2014, 80, 1670-1678. [CrossRef] [PubMed]

73. Tristezza, M.; Tufariello, M.; Capozzi, V.; Spano, G.; Mita, G.; Grieco, F. The Oenological Potential of Hanseniaspora uvarum in Simultaneous and Sequential Co-fermentation with Saccharomyces cerevisiae for Industrial Wine Production. Front. Microbiol. 2016, 7. [CrossRef] [PubMed]

74. Russo, P.; Tufariello, M.; Renna, R.; Tristezza, M.; Taurino, M.; Palombi, L.; Capozzi, V.; Rizzello, C.G.; Grieco, F. New Insights into the Oenological Significance of Candida zemplinina: Impact of Selected Autochthonous Strains on the Volatile Profile of Apulian Wines. Microorganisms 2020, 8, 628. [CrossRef]

75. González-Royo, E.; Pascual, O.; Kontoudakis, N.; Esteruelas, M.; Esteve-Zarzoso, B.; Mas, A.; Canals, J.M.; Zamora, F. Oenological consequences of sequential inoculation with non-Saccharomyces yeasts (Torulaspora delbrueckii or Metschnikowia pulcherrima) and Saccharomyces cerevisiae in base wine for sparkling wine production. Eur. Food Res. Technol. 2015, 240, 999-1012. [CrossRef]

76. Renault, P.E.; Albertin, W.; Bely, M. An innovative tool reveals interaction mechanisms among yeast populations under oenological conditions. Appl. Microbiol. Biotechnol. 2013, 97, 4105-4119. [CrossRef]

77. Gobert, A.; Tourdot-Maréchal, R.; Morge, C.; Sparrow, C.; Liu, Y.; Quintanilla-Casas, B.; Vichi, S.; Alexandre, H. Non-Saccharomyces Yeasts Nitrogen Source Preferences: Impact on Sequential Fermentation and Wine Volatile Compounds Profile. Front. Microbiol. 2017, 8. [CrossRef]

78. Hansen, E.H.; Nissen, P.; Sommer, P.; Nielsen, J.C.; Arneborg, N. The effect of oxygen on the survival of non-Saccharomyces yeasts during mixed culture fermentations of grape juice with Saccharomyces cerevisiae. J. Appl. Microbiol. 2001, 91, 541-547. [CrossRef]

79. Vasserot, Y.; Mornet, F.; Jeandet, P. Acetic acid removal by Saccharomyces cerevisiae during fermentation in oenological conditions. Metabolic consequences. Food Chem. 2010, 119, 1220-1223. [CrossRef]

80. Jackowetz, J.N.; Dierschke, S.; Mira de Orduña, R. Multifactorial analysis of acetaldehyde kinetics during alcoholic fermentation by Saccharomyces cerevisiae. Food Res. Int. 2011, 44, 310-316. [CrossRef]

81. Legras, J.L.; Karst, F. Optimisation of interdelta analysis for Saccharomyces cerevisiae strain characterization. FEMS Microbiol. Lett. 2003, 221, 249-255. [CrossRef]

82. Garofalo, C.; Berbegal, C.; Grieco, F.; Tufariello, M.; Spano, G.; Capozzi, V. Selection of indigenous yeast strains for the production of sparkling wines from native Apulian grape varieties. Int. J. Food Microbiol. 2018, 285, 7-17. [CrossRef] [PubMed]

83. Jin, X.; Chen, W.; Chen, H.; Chen, W.; Zhong, Q. Combination of Lactobacillus plantarum and Saccharomyces cerevisiae DV10 as Starter Culture to Produce Mango Slurry: Microbiological, Chemical Parameters and Antioxidant Activity. Molecules 2019, 24, 4349. [CrossRef] [PubMed]

84. Seguinot, P.; Bloem, A.; Brial, P.; Meudec, E.; Ortiz-Julien, A.; Camarasa, C. Analyzing the impact of the nature of the nitrogen source on the formation of volatile compounds to unravel the aroma metabolism of two non-Saccharomyces strains. Int. J. Food Microbiol. 2020, 316, 108441. [CrossRef] [PubMed]

85. Chua, J.Y.; Lu, Y.; Liu, S.Q. Evaluation of five commercial non-Saccharomyces yeasts in fermentation of soy (tofu) whey into an alcoholic beverage. Food Microbiol. 2018, 76, 533-542. [CrossRef]

86. Prior, K.J.; Bauer, F.F.; Divol, B. The utilization of nitrogenous compounds by commercial non-Saccharomyces yeasts associated with wine. Food Microbiol. 2019, 79, 75-84. [CrossRef]

87. Ivit, N.N.; Kemp, B. The Impact of Non-Saccharomyces Yeast on Traditional Method Sparkling Wine. Fermentation 2018, 4, 73. [CrossRef] 
88. Nardi, T.; Panero, L.; Petrozziello, M.; Guaita, M.; Tsolakis, C.; Cassino, C.; Vagnoli, P.; Bosso, A. Managing wine quality using Torulaspora delbrueckii and Oenococcus oeni starters in mixed fermentations of a red Barbera wine. Eur. Food Res. Technol. 2019, 245, 293-307. [CrossRef]

89. Chandra, M.; Oro, I.; Ferreira-Dias, S.; Malfeito-Ferreira, M. Effect of Ethanol, Sulfur Dioxide and Glucose on the Growth of Wine Spoilage Yeasts Using Response Surface Methodology. PLoS ONE 2015, 10, e0128702. [CrossRef]

90. Ciani, M.; Capece, A.; Comitini, F.; Canonico, L.; Siesto, G.; Romano, P. Yeast Interactions in Inoculated Wine Fermentation. Front. Microbiol. 2016, 7. [CrossRef]

91. Pinu, F.R.; Edwards, P.J.B.; Gardner, R.C.; Villas-Boas, S.G. Nitrogen and carbon assimilation by Saccharomyces cerevisiae during Sauvignon blanc juice fermentation. FEMS Yeast Res. 2014, 14, 1206-1222. [CrossRef]

92. Barbosa, C.; Lage, P.; Esteves, M.; Chambel, L.; Mendes-Faia, A.; Mendes-Ferreira, A. Molecular and Phenotypic Characterization of Metschnikowia pulcherrima Strains from Douro Wine Region. Fermentation 2018, 4, 8. [CrossRef]

93. Escribano-Viana, R.; Portu, J.; Garijo, P.; López, R.; Santamaría, P.; López-Alfaro, I.; Gutiérrez, A.R.; González-Arenzana, L. Effect of the Sequential Inoculation of Non-Saccharomyces/Saccharomyces on the Anthocyans and Stilbenes Composition of Tempranillo Wines. Front. Microbiol. 2019, 10. [CrossRef]

94. Benito, Á.; Calderón, F.; Palomero, F.; Benito, S. Combine Use of Selected Schizosaccharomyces pombe and Lachancea thermotolerans Yeast Strains as an Alternative to theTraditional Malolactic Fermentation in Red Wine Production. Molecules 2015, 20, 9510-9523. [CrossRef] [PubMed]

95. Benito, Á.; Calderón, F.; Benito, S. The Combined Use of Schizosaccharomyces pombe and Lachancea thermotolerans-Effect on the Anthocyanin Wine Composition. Molecules 2017, 22, 739. [CrossRef] [PubMed]

96. Benito, Á.; Calderón, F.; Benito, S. Combined Use of S. pombe and L. thermotolerans in Winemaking. Beneficial Effects Determined Through the Study of Wines' Analytical Characteristics. Molecules 2016, 21, 1744. [CrossRef] [PubMed]

97. King, E.S.; Kievit, R.L.; Curtin, C.; Swiegers, J.H.; Pretorius, I.S.; Bastian, S.E.P.; Leigh Francis, I. The effect of multiple yeasts co-inoculations on Sauvignon Blanc wine aroma composition, sensory properties and consumer preference. Food Chem. 2010, 122, 618-626. [CrossRef]

98. Gustafsson, F.S.; Jiranek, V.; Neuner, M.; Scholl, C.M.; Morgan, S.C.; Durall, D.M. The Interaction of Two Saccharomyces cerevisiae Strains Affects Fermentation-Derived Compounds in Wine. Fermentation 2016, $2,9$. [CrossRef]

99. Berbegal, C.; Garofalo, C.; Russo, P.; Pati, S.; Capozzi, V.; Spano, G. Use of Autochthonous Yeasts and Bacteria in Order to Control Brettanomyces bruxellensis in Wine. Fermentation 2017, 3, 65. [CrossRef]

100. Berbegal, C.; Spano, G.; Fragasso, M.; Grieco, F.; Russo, P.; Capozzi, V. Starter cultures as biocontrol strategy to prevent Brettanomyces bruxellensis proliferation in wine. Appl. Microbiol. Biotechnol. 2018, 102, 569-576. [CrossRef]

101. Capozzi, V.; Fragasso, M.; Russo, P. Microbiological Safety and the Management of Microbial Resources in Artisanal Foods and Beverages: The Need for a Transdisciplinary Assessment to Conciliate Actual Trends and Risks Avoidance. Microorganisms 2020, 8, 306. [CrossRef]

102. Berbegal, C.; Borruso, L.; Fragasso, M.; Tufariello, M.; Russo, P.; Brusetti, L.; Spano, G.; Capozzi, V. A Metagenomic-Based Approach for the Characterization of Bacterial Diversity Associated with Spontaneous Malolactic Fermentations in Wine. Int. J. Mol. Sci. 2019, 20, 3980. [CrossRef] [PubMed]

103. Englezos, V.; Cachón, D.C.; Rantsiou, K.; Blanco, P.; Petrozziello, M.; Pollon, M.; Giacosa, S.; Río Segade, S.; Rolle, L.; Cocolin, L. Effect of mixed species alcoholic fermentation on growth and malolactic activity of lactic acid bacteria. Appl. Microbiol. Biotechnol. 2019, 103, 7687-7702. [CrossRef] [PubMed]

104. Balmaseda, A.; Bordons, A.; Reguant, C.; Bautista-Gallego, J. Non-Saccharomyces in Wine: Effect Upon Oenococcus oeni and Malolactic Fermentation. Front. Microbiol. 2018, 9, 534. [CrossRef] [PubMed]

105. Capozzi, V.; Berbegal, C.; Tufariello, M.; Grieco, F.; Spano, G.; Grieco, F. Impact of co-inoculation of Saccharomyces cerevisiae, Hanseniaspora uvarum and Oenococcus oeni autochthonous strains in controlled multi starter grape must fermentations. LWT 2019, 109, 241-249. [CrossRef]

106. Willaert, R.; Kasas, S.; Devreese, B.; Dietler, G. Yeast Nanobiotechnology. Fermentation 2016, 2, 18. [CrossRef] 
107. Botstein, D.; Fink, G.R. Yeast: An Experimental Organism for 21st Century Biology. Genetics 2011, 189, 695-704. [CrossRef]

108. Walker, R.S.K.; Pretorius, I.S. Applications of Yeast Synthetic Biology Geared towards the Production of Biopharmaceuticals. Genes 2018, 9, 340. [CrossRef]

(C) 2020 by the authors. Licensee MDPI, Basel, Switzerland. This article is an open access article distributed under the terms and conditions of the Creative Commons Attribution (CC BY) license (http://creativecommons.org/licenses/by/4.0/). 